Jurnal Kimia Sains dan Aplikasi 21 (2) (2018):75-79
ISSN: 1410-8917
Jurnal Kimia
A-ISSN: 2597-9914 \&

\title{
Zeolite and Charcoal as Potential Adsorbents in Tubs of Oxydation Ditch I and Oxydation Ditch II at Water Treatment and Composting Plant (WTCP) PT. Djarum Kudus
}

\author{
Rissa Kharismawati ${ }^{\mathrm{a}^{*}}$, Redi Joko Prasetyo ${ }^{\mathrm{b}}$, Yayuk Astuti ${ }^{\mathrm{a}}$ \\ a Chemistry Department, Faculty of Sciences and Mathematics, Diponegoro University, Jalan Prof. Soedarto, Tembalang, Semarang \\ b P. T. Djarum Kudus, Kudus \\ * Corresponding author: rissaakharisma@gmail.com
}

\begin{tabular}{l}
\hline Article Info \\
\hline Keywords: \\
adsorbent, \\
adsorption, zeolite, \\
charcoal, chalk, \\
spectrophotometry, \\
pH, COD
\end{tabular}

Kata Kunci: adsorben,adsorpsi, zeolit, charcoal, chalk, spektrofotometri, $\mathrm{pH}, \mathrm{COD}$.

\begin{abstract}
This study aims to determine the mass of zeolite and charcoal required as lime nutrient adsorbent $\left(\mathrm{Ca}(\mathrm{OH})_{2}\right)$ in reducing $\mathrm{pH}$, TSS, COD, and SV values in tubs of oxidation of ditches I and II in Water Treatment and Composting Plant (WTCP) PT. Djarum Kudus with the principle of adsorption. The methods used were jar test and spectrophotometry. The adsorbents used were chalk $\left(\mathrm{Ca}(\mathrm{OH})_{2}\right)$, zeolite, and charcoal added to the tub samples of oxydation ditch I and oxidation ditch II by variation of mass for every adsorbent, that were 2 gram, 4 gram and 6 gram. The results showed that zeolite and charcoal were more effective than charchoal in lowering $\mathrm{pH}$, COD, TSS and SV values in tubs of oxidation ditches I and II on the addition of 6 gram in $500 \mathrm{ml}$ of sample.
\end{abstract}

\section{Abstrak}

Penelitian ini bertujuan untuk menentukan massa zeolit dan charcoal yang ditambahkan sebagai adsorben pengganti kapur $\left(\mathrm{Ca}(\mathrm{OH})_{2}\right)$ dalam penurunan nilai $\mathrm{pH}$, TSS, COD, dan SV pada bak oxydation ditch I dan II di Water Treatment and Composting Plant (WTCP) PT. Djarum Kudus dengan prinsip adsorpsi. Metode yang digunakan dalam percobaan ini adalah jar test dan spektrofotometri. Sampel yang diuji adalah kapur $\left(\mathrm{Ca}(\mathrm{OH})_{2}\right)$, zeolit, dan charcoal yang ditambahkan pada sampel bak oxydation ditch I dan oxydation ditch II dengan variasi massa untuk seluruh adsorben 2 gram, 4 gram, dan 6 gram. Berdasarkan percobaan yang telah dilakukan dikertahui bahwa zeolit dan charcoal efektif dalam menggantikan peran kapur sebagai adsorben dalam menurunkan nilai $\mathrm{pH}, \mathrm{COD}$, TSS dan SV pada bak oxydation ditch I dan II pada penambahan 6 gram dalam $500 \mathrm{ml}$ sampel.

\section{Pendahuluan}

PT Djarum Oasis Kudus merupakan salah satu jenis industri yang bergerak dalam bidang produksi rokok. Produk rokok dihasilkan dari bahan baku utama yaitu cengkeh dan tembakau. Proses pembuatan rokok tersebut menghasilkan berbagai macam limbah. Limbah yang dihasilkan dari proses pembuatan rokok terdiri dari tiga jenis air kotor. Tiga jenis air kotor tersebut adalah air kotor domestik (berasal dari aktivitas dapur, kamar mandi dan mushola), air kotor casing (berasal dari pencucian alat-alat produksi dan sisa pencampuran saos pada rokok) dan air kotor clove (berasal dari proses steam cengkeh). Proses pengolahan air kotor di PT Djarum dikelola oleh unit Water Treatment and Composting Plant (WTCP), dengan sistem pengolahan menggunakan lumpur aktif (Activated Sludge).

Bak oxydation ditch (OD) adalah bak biologis, karena pada bak ini menggunakan bakteri aerobik untuk mendegradasi bahan-bahan organik yang terdapat pada air kotor. Pada bak ini, air kotor yang berasal dari bak turbo coagulator dan bak domestik dimasukan melalui inlet yang kemudian terbagi menjadi bak oxydation ditch 1 dan oxydation ditch 2 dan juga dilakukan proses aerasi menggunakan mammoth rotor. Saat ini, PT Djarum Oasis 
Kudus menggunakan kapur $\left(\mathrm{Ca}(\mathrm{OH})_{2}\right)$ sebagai koagulan dalam bak OD 1 dan OD 2, namun $\mathrm{pH}$ yang dihasilkan sekitar 10-11 (belum optimal). Nilai pH tersebut dikarenakan kapur $\left(\mathrm{Ca}(\mathrm{OH})_{2}\right)$ adalah basa dengan kekuatan sedang sehingga akan menghasilkan $\mathrm{pH}$ pada keadaan basa.

Hasil penjernihan limbah pada bak oxydation ditch I dan II dengan penambahan kapur kurang optimal dalam menurunkan nilai $\mathrm{pH}$ karena limbah masih menunjukkan $\mathrm{pH}$ 10-11 sehingga tidak bisa dialirkan ke lingkungan karena masih membahayakan. Menurut Peraturan Daerah Jawa Tengah No.5 Tahun 2012 tentang Baku Mutu Limbah Cair untuk Industri Rokok, nilai pH maksimum yaitu 6-9 [1]. Salah satu usaha penanggulangan dampak dari limbah industri terhadap lingkungan sekitar yaitu melakukan pengolahan limbah dengan metode adsorpsi. Adsorpsi merupakan proses penyerapan yang terjadi pada permukaan suatu padatan (zat lain) [2]. Keuntungan dari metode adsorpsi yaitu mudah dilakukan, juga efektivitasnya cukup tinggi dan biaya yang diperlukan cukup rendah [3]. Zat padat pada proses adsorpsi ini disebut sebagai adsorben, sedangkan molekul lain yang terserap pada permukaan zat pada disebut sebagai adsorbat. Beberapa contoh adsorben (zat penjerap) yang dapat digunakan pada proses adsorpsi adalah karbon aktif [4], silika dan alumina, zeolit [5], arang tulang, dan oksida-oksida logam [6]. Pada penelitian ini menggunakan adsorben zeolit dan karbon aktif (charcoal). Karbon aktif adalah karbon yang diproses sedemikian rupa sehingga pori-porinya terbuka, dan dengan demikian akan mempunyai daya serap yang tinggi. Karbon aktif merupakan karbon yang akan membentuk amorf, yang sebagian besar terdiri dari karbon yang bebas serta memiliki permukaan dalam (internal surface), sehingga mempunyai daya serap yang baik [7]. Sedangkan, zeolit adalah kristal aluminasilikat hidrat dengan struktur kerangka tiga dimensi yang tersusun atas tetrahedral $\left(\mathrm{SiO}_{4}\right)^{4^{-}}$dan $\left(\mathrm{AlO}_{4}\right)^{5-}$ dengan atom oksigen sebagai penghubungnya. Melimpahnya zeolit alam di Indonesia memberikan peluang menggunakannya untuk berbagai aplikasi [8]. Oleh karena itu, pada penelitian ini akan membahas pemanfaatan zeolit dan charcoal (Arang aktif) yang berasal dari pohon trembesi yang sudah tua sebagai adsorben pengganti kapur $\left(\mathrm{Ca}(\mathrm{OH})_{2}\right)$ pada bak OD 1 dan 2 dengan variasi massa yang ditambahkan dan menggunakan parameter nilai $\mathrm{pH}, \mathrm{SV}, \mathrm{COD}$, dan TSS.

\section{Metode Penelitian}

Bahan

Bahan yang digunakan dalam percobaan ini adalah sampel berupa limbah cair yang diperoleh dari oxydation ditch I dan II, zeolit teraktivasi, charcoal, kapur $\left(\mathrm{Ca}(\mathrm{OH})_{2}\right)$, aquades, dan reagen COD.

\section{Penghalusan Zeolit dan Charcoal}

Zeolit (masih dalam bentuk kasar) dihaluskan dengan mortar dan stamper untuk memperluas permukaan.. Lalu, zeolit dari hasil tumbukkan diayak dengan menggunakan saringan. Selanjutnya, zeolit yang telah halus dimasukkan dalam plastik klip.
Dilakukan pengulangan langkah 1-3 dengan menggunakan bahan charcoal.

\section{Pengaktivasian Zeolit}

Zeolit yang telah halus di letakkan dalam loyang lalu dimasukkan dalam oven. Zeolit diaktivasi dengan metode sonikasi yaitu dilakukan dengan suhu $300^{\circ} \mathrm{C}$ selama 3 jam. Setelah 3 jam, dilakukan pengambilan zeolit dalam oven lalu di dapatkan hasil zeolit yang teraktivasi.

\section{Adsorpsi Sampel Oxydation Ditch I}

Sampel limbah dari oxydation ditch I dimasukkan ke dalam gelas beker masing-masing $500 \mathrm{ml}$. Lalu, ditambahkan kapur $\left(\mathrm{Ca}(\mathrm{OH})_{2}\right)$, zeolit, dan charcoal terhadap sampel oxydation ditch I dengan variasi massa yang ditambahkan 2 gram, 4 gram, 6 gram, serta 0 gram sebagai control. Kemudian dilakukan jar test selama 10 menit pada $200 \mathrm{rpm}$. Selanjutnya dilakukan pengukuran sludge volume (SV) dengan gelas ukur $1000 \mathrm{ml}$ selama 30 menit, pengukuran $\mathrm{pH}$ dengan $\mathrm{pH}$ meter, pengukuran TSS dan COD dengan spektrofotometer. Langkah ini juga dilakukan terhadap sampel limbah dari oxydation ditch II.

\section{Hasil dan Pembahasan}

Penelitian ini bertujuan untuk menentukan massa zeolit dan charcoal yang ditambahkan sebagai adsorben pengganti kapur $\left(\mathrm{Ca}(\mathrm{OH})_{2}\right)$ dalam penurunan nilai $\mathrm{pH}$, TSS, COD, dan SV pada bak oxydation ditch I dan II.

\section{Bak Oxydation Ditch 1}

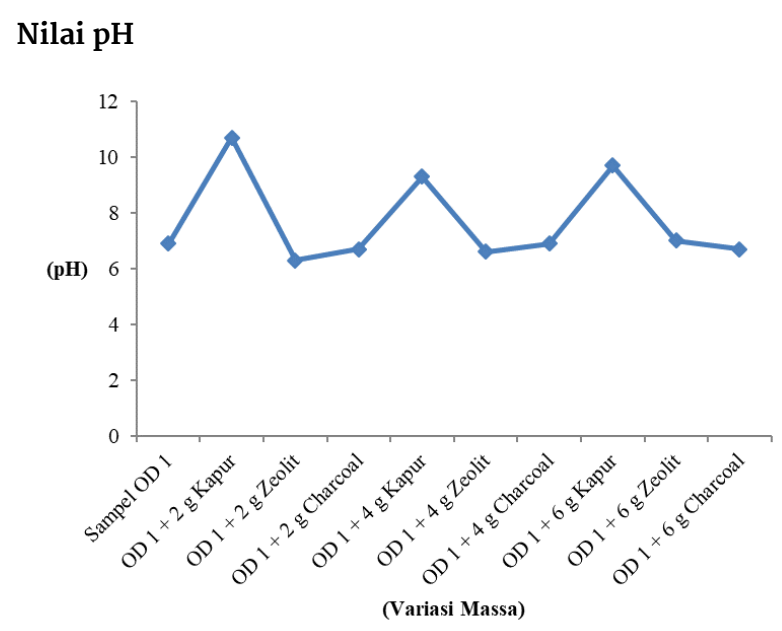

Gambar 1 Pengaruh penambahan kapur, zeolit, dan charcoal terhadap $\mathrm{pH}$

Gambar 1 menunjukkan bahwa penambahan kapur belum mampu menurunkan $\mathrm{pH}$ (menetralkan $\mathrm{pH}$ ) pada sampel. Terlihat pada $\mathrm{pH}$ pada saat penambahan kapur $\mathrm{Ca}(\mathrm{OH})_{2}$ sebelum penambahan kapur $\mathrm{Ca}(\mathrm{OH})_{2}, \mathrm{pH}$ awal sampel yaitu 6.9 dan setelah penambahan kapur $\mathrm{Ca}(\mathrm{OH})_{2} 2$ gram $\mathrm{pH}$ berubah menjadi 10.7, penambahan kapur $\mathrm{Ca}(\mathrm{OH})_{2} 4$ gram $\mathrm{pH}$ sebesar 9.3, dan 6 gram $\mathrm{pH}$ sebesar 9.7. Saat penambahan zeolit 2 gram $\mathrm{pH}$ menjadi 6.7, penambahan zeolit 4 gram menjadi 6.6 , dan penambahan zeolit 6 gram menjadi 7.0. Lalu saat penambahan 2 gram charcoal $\mathrm{pH}$ menjadi 6.7, penambahan 4 gram charcoal $\mathrm{pH}$ menjadi 6.9 , dan saat 
penambahan 6 gram menjadi 6.7. pH pada bak oxydation ditch perlu dioptimalkan agar mikroba dapat bekerja secara maksimal dan $\mathrm{pH}$ tetap optimal ketika di alirkan ke dalam bak clarifier. Berdasarkan grafik di atas, charcoal dan zeolit efektif dalam menurunkan nilai $\mathrm{pH}$ dibandingkan dengan kapur $\left(\mathrm{Ca}(\mathrm{OH})_{2}\right)$

\section{Nilai Sludge Volume(SV)}

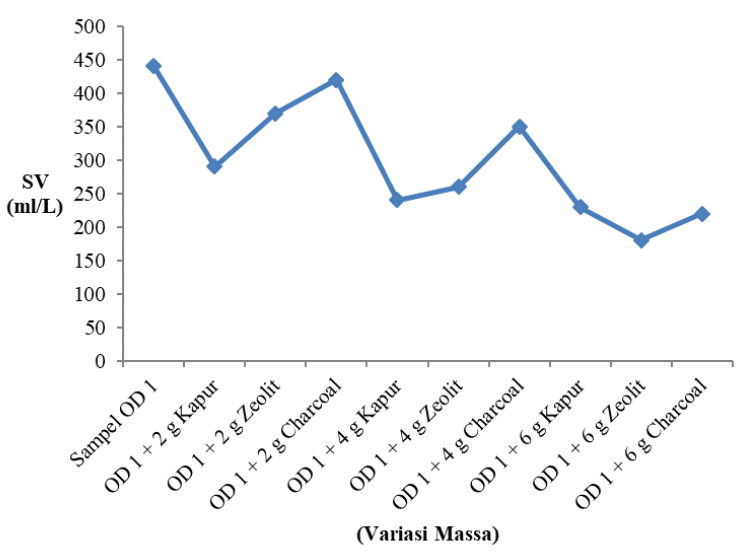

Gambar 2 Pengaruh penambahan kapur, zeolit, dan charcoal terhadap SV

Gambar 2 menunjukkan bahwa penambahan kapur mampu menurunkan SV tetapi belum optimal pada sampel. Terlihat nilai SV pada saat penambahan kapur $\mathrm{Ca}(\mathrm{OH})_{2}$ sebelum penambahan kapur $\mathrm{Ca}(\mathrm{OH})_{2}$, SV awal sampel yaitu 440 dan setelah penambahan kapur $\mathrm{Ca}(\mathrm{OH})_{2} 2$ gram SV berubah menjadi 290, penambahan kapur $\mathrm{Ca}(\mathrm{OH})_{2} 4$ gram SV sebesar 240, dan 6 gram SV sebesar 230. Saat penambahan zeolit 2 gram SV menjadi 370 , penambahan zeolit 4 gram menjadi 260 , dan penambahan zeolit 6 gram menjadi 180. Lalu saat penambahan 2 gram charcoal SV menjadi 420, penambahan 4 gr charcoal SV menjadi 350, dan saat penambahan 6 gram menjadi 220. Semakin rendah nilai SV maka semakin efektif. Dilihat dari grafik diatas zeolit dan charcoal sudah optimal dalam menurunkan nilai SV. Hasil nilai SV di atas dapat diurutkan yang efektif dapat menurunkan nilai SV yaitu zeolit, charcoal, lalu kapur $\mathrm{Ca}(\mathrm{OH})_{2}$.

\section{Nilai COD}

Gambar 3 menunjukkan bahwa penambahan kapur belum mampu menurunkan COD pada sampel. Terlihat nilai COD pada saat penambahan kapur $\mathrm{Ca}(\mathrm{OH})_{2}$ dan sebelum penambahan kapur $\mathrm{Ca}(\mathrm{OH})_{2}$, $\mathrm{COD}$ awal sampel yaitu 102 dan setelah penambahan kapur $\mathrm{Ca}(\mathrm{OH})_{2} 2$ gram COD berubah menjadi 199, penambahan kapur $\mathrm{Ca}(\mathrm{OH})_{2} 4$ gram COD sebesar 141, dan 6 gram COD sebesar 115. Saat penambahan zeolit 2 gram COD menjadi 160 , penambahan zeolit 4 gram menjadi 81 , dan penambahan zeolit 6 gram menjadi 72. Lalu saat penambahan 2 gram charcoal COD menjadi 132, penambahan 4 gram charcoal COD menjadi 99, dan saat penambahan 6 gram charcoal, nilai COD menjadi 83.

Nilai COD dapat mempengaruhi seberapa besar pencemaran yang terjadi pada lingkungan tersebut sehingga harus di dapatkan nilai COD yang tidak terlalu tinggi. Berdasarkan grafik diatas, zeolit dan charcoal efektif dalam menurunkan nilai COD pada bak oxydation ditch I.

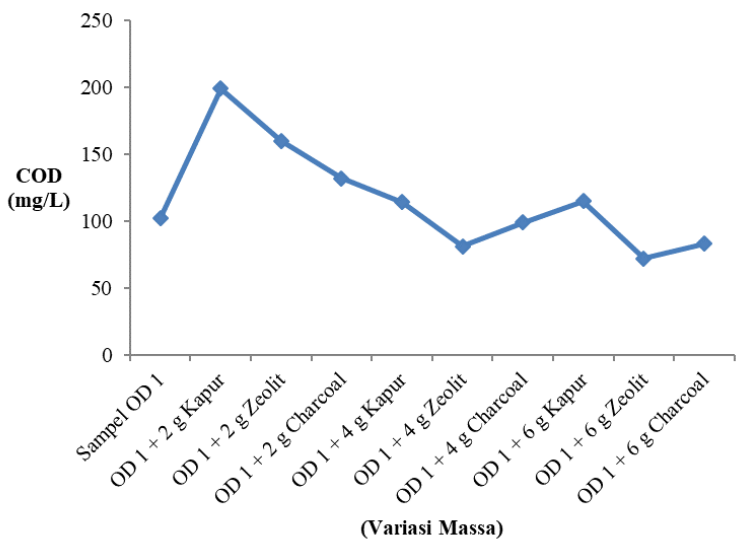

Gambar 3 Pengaruh penambahan kapur, zeolit, dan charcoal terhadap COD

\section{Nilai TSS}

Gambar 4 menunjukkan bahwa penambahan kapur mampu menurunkan TSS pada sampel. Terlihat nilai TSS pada saat penambahan kapur $\mathrm{Ca}(\mathrm{OH})_{2}$ sebelum penambahan kapur $\mathrm{Ca}(\mathrm{OH})_{2}$, TSS awal sampel yaitu 73 dan setelah penambahan kapur $\mathrm{Ca}(\mathrm{OH})_{2} 2$ gram TSS berubah menjadi 12, penambahan kapur $\mathrm{Ca}(\mathrm{OH})_{2} 4$ gram TSS sebesar 8, dan 6 gram TSS sebesar 7. Saat penambahan zeolit 2 gram TSS menjadi 9, penambahan zeolit 4 gram menjadi 14, dan penambahan zeolit 6 gram menjadi 15. Lalu saat penambahan 2 gram charcoal TSS menjadi 91, penambahan 4 gram charcoal TSS menjadi 20, dan saat penambahan 6 gram menjadi 27.

TSS merupakan padatan yang menyebabkan kekeruhan. Agar mendapatkan hasil air yang jernih maka harus mendapatkan nilai TSS yang rendah. Pada grafik diatas, charcoal dan zeolit kurang efektif menurunkan nilai TSS dibandingkan dengan kapur $\left(\mathrm{Ca}(\mathrm{OH})_{2}\right)$ tetapi nilai yang di dapat oleh charcoal dan zeolit tidak terlalu tinggi.

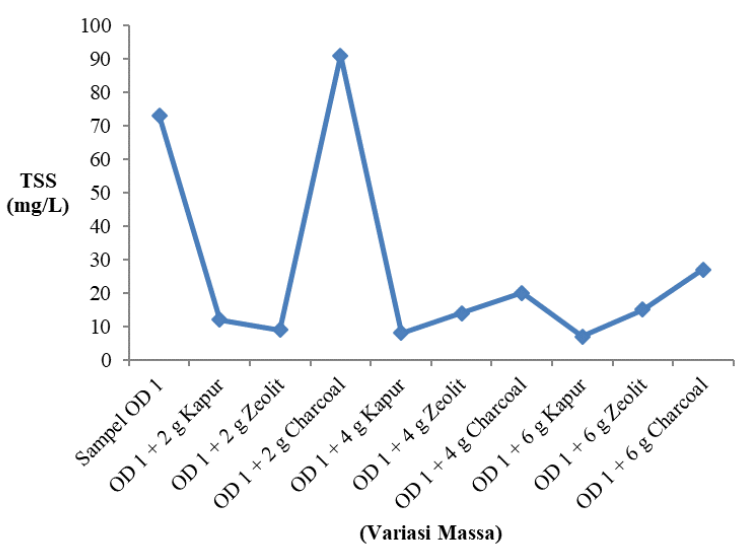

Gambar 4 Pengaruh penambahan kapur, zeolit, dan charcoal terhadap TSS 


\section{Bak Oxydation Ditch II}

Nilai $\mathrm{pH}$

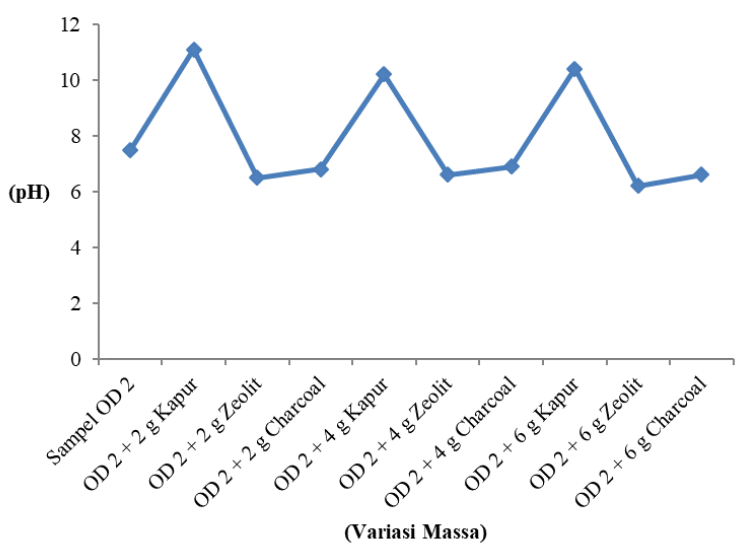

Gambar 5 Pengaruh penambahan kapur, zeolit, dan charcoal terhadap $\mathrm{pH}$

Gambar 5 menunjukkan bahwa penambahan kapur belum mampu menurunkan $\mathrm{pH}$ (menetralkan $\mathrm{pH}$ ) pada sampel. Terlihat pada nilai $\mathrm{pH}$ pada saat penambahan kapur $\mathrm{Ca}(\mathrm{OH})_{2}$ sebelum penambahan kapur $\mathrm{Ca}(\mathrm{OH})_{2}, \mathrm{pH}$ awal sampel yaitu 7.5 dan setelah penambahan kapur $\mathrm{Ca}(\mathrm{OH})_{2} 2$ gram $\mathrm{pH}$ berubah menjadi 11.1, penambahan kapur $\mathrm{Ca}(\mathrm{OH})_{2} 4$ gram $\mathrm{pH}$ sebesar 10.2, dan 6 gram $\mathrm{pH}$ sebesar 10.4. Saat penambahan zeolit 2 gram $\mathrm{pH}$ menjadi 6.5, penambahan zeolit 4 gram menjadi 6.6 , dan penambahan zeolit 6 gram menjadi 6.2. Lalu saat penambahan 2 gram charcoal $\mathrm{pH}$ menjadi 6.8, penambahan 4 gram charcoal $\mathrm{pH}$ menjadi 6.9 , dan saat penambahan 6 gram menjadi 6.6. Berdasarkan grafik di atas, charcoal dan zeolit efektif dalam menurunkan atau mengoptimalkan nilai $\mathrm{pH}$ dibanding dengan kapur $\left(\mathrm{Ca}(\mathrm{OH})_{2}\right)$

Nilai Sludge Volume (SV)

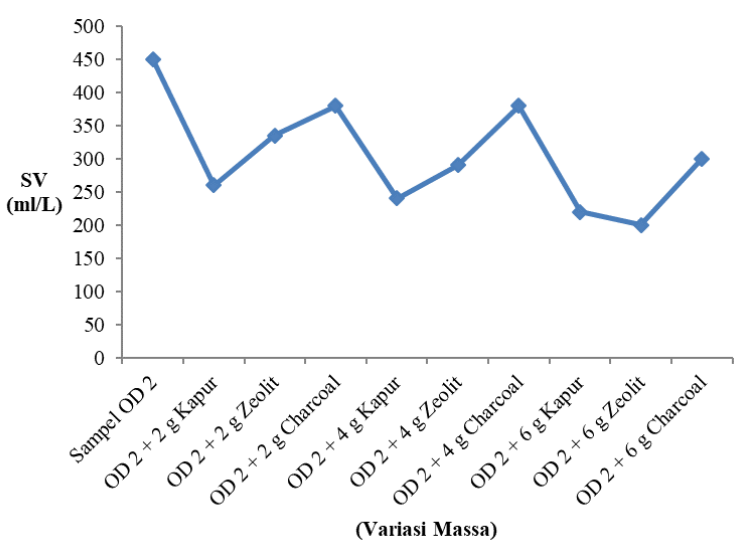

Gambar 6 Pengaruh penambahan kapur, zeolit, dan charcoal terhadap SV

Gambar 6 menunjukkan bahwa penambahan kapur mampu menurunkan nilai SV pada sampel tetapi kurang optimal. Terlihat pada nilai SV saat penambahan kapur $\mathrm{Ca}(\mathrm{OH})_{2}$ dan sebelum penambahan kapur $\mathrm{Ca}(\mathrm{OH})_{2}, \mathrm{SV}$ awal sampel yaitu 450 dan setelah penambahan kapur $\mathrm{Ca}(\mathrm{OH})_{2} 2$ gram SV berubah menjadi 260, penambahan kapur $\mathrm{Ca}(\mathrm{OH})_{2} 4$ gram SV sebesar 240, dan 6 gram SV sebesar 220. Saat penambahan zeolit 2 gram SV menjadi 335, penambahan zeolit 4 gram menjadi 290, dan penambahan zeolit 6 gram menjadi 200. Lalu saat penambahan 2 gram charcoal SV menjadi 380, penambahan 4 gram charcoal SV menjadi 380, dan saat penambahan 6 gram menjadi 300.

Berdasarkan hasil yang di dapatkan, zeolit dan charcoal memiliki nilai SV lebih kecil dari kapur $\mathrm{Ca}(\mathrm{OH})_{2}$ tetapi jika dilihat dari selisih penurunan nilai SV, urutan yang paling besar yaitu zeolit $(45-90 \mathrm{ml} / \mathrm{L})>\operatorname{charcoal}(80$ $\mathrm{ml} / \mathrm{L})>\operatorname{kapur} \mathrm{Ca}(\mathrm{OH}) 2(20 \mathrm{ml} / \mathrm{L})$. Sehingga zeolit dan charcoal efektif dalam menurunkan nilai SV.

\section{Nilai COD}

Gambar 7 menunjukkan bahwa penambahan kapur mampu menurunkan COD pada sampel tetapi belum optimal. Terlihat pada nilai COD saat penambahan kapur $\mathrm{Ca}(\mathrm{OH})_{2}$ dan sebelum penambahan kapur $\mathrm{Ca}(\mathrm{OH})_{2}$, COD awal sampel yaitu 126 dan setelah penambahan kapur $\mathrm{Ca}(\mathrm{OH})_{2} 2$ gram COD berubah menjadi 155, penambahan kapur $\mathrm{Ca}(\mathrm{OH})_{2} 4$ gram COD sebesar 180, dan 6 gram COD sebesar 100. Saat penambahan zeolit 2 gram COD menjadi 78 , penambahan zeolit 4 gram menjadi 56 , dan penambahan zeolit 6 gram menjadi 151. Lalu saat penambahan 2 gram charcoal COD menjadi 90, penambahan 4 gram charcoal COD menjadi 150, dan saat penambahan 6 gram menjadi 97.

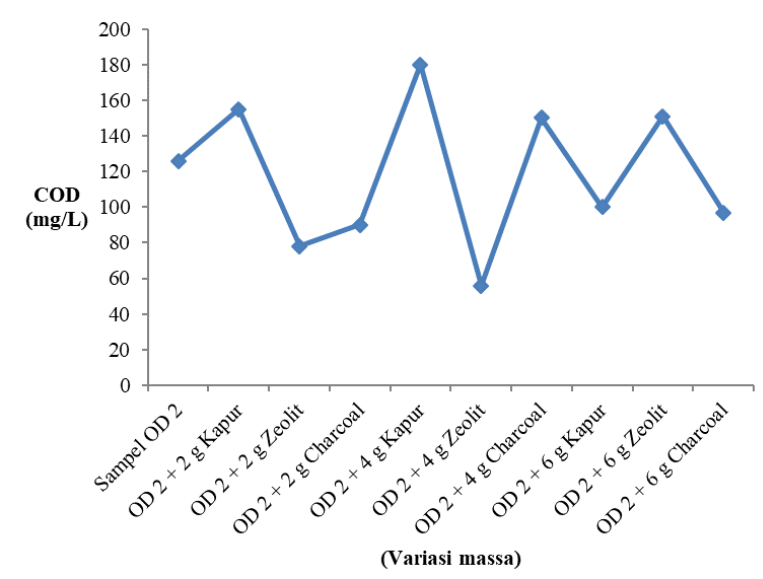

Gambar 7 Pengaruh penambahan kapur, zeolit, dan charcoal terhadap COD

Hasil yang didapat menunjukkan bahwa material yang optimal dalam menurunkan nilai COD adalah zeolit tetapi pada penambahan zeolit 6 gram terdapat kenaikan nilai COD yang begitu besar dikarenakan kesalahan saat melakukan penelitian yaitu sampel OD 2 yang ditambah 6 gram zeolit dalam reagen COD secara tidak sengaja di homogenkan sehingga mengakibatkan nilai COD yang begitu besar dimana seharusnya nilai COD mengalami penurunan seperti pada nilai COD sampel oxydation ditch I.

\section{Nilai TSS}

Gambar 8 menunjukkan bahwa penambahan kapur mampu menurunkan TSS pada sampel tetapi belum optimal. Terlihat pada nilai TSS saat penambahan kapur $\mathrm{Ca}(\mathrm{OH})_{2}$ dan sebelum penambahan kapur $\mathrm{Ca}(\mathrm{OH})_{2}$, TSS 
awal sampel yaitu 58 dan setelah penambahan kapur $\mathrm{Ca}(\mathrm{OH})_{2} 2$ gram TSS berubah menjadi 10, penambahan kapur $\mathrm{Ca}(\mathrm{OH})_{2} 4$ gram TSS sebesar 15, dan 6 gram TSS sebesar 13. Saat penambahan zeolit 2 gram TSS menjadi 16, penambahan zeolit 4 gram menjadi 8 , dan penambahan zeolit 6 gram menjadi 13. Lalu saat penambahan 2 gram charcoal TSS menjadi 20, penambahan 4 gram charcoal TSS menjadi 43, dan saat penambahan 6 gram menjadi 39.

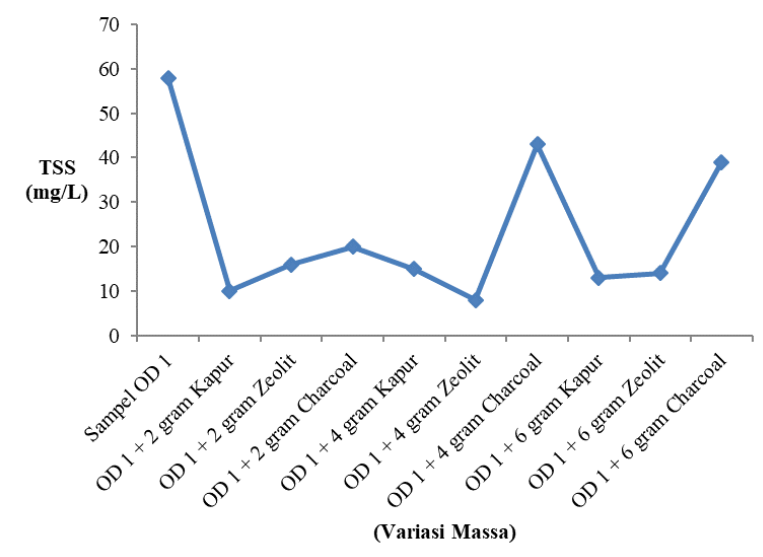

Gambar 8 Pengaruh penambahan kapur, zeolit, dan charcoal terhadapTSS

\section{Kesimpulan}

Zeolit dan charcoal efektif dalam menggantikan peran kapur sebagai adsorben pada bak oxydation ditch I dan II dalam menurunkan nilai pH, COD, TSS dan SV pada penambahan 6 gram dalam $500 \mathrm{ml}$ sampel.

\section{Daftar Pustaka}

[1] Peraturan Daerah Jawa Tengah No.5 Tahun 2012 Tentang Perubahan Atas Peraturan Daerah Provinsi Jawa Tengah No. 10 Tahun 2004 Tentang Baku Mutu Air Limbah., in: D.J. Tengah (Ed.), Semarang, 2012.

[2] Devika Tesnar Winda, Rum Hastuti, Abdul Haris, Pengaruh Penambahan PVA-Sulfonasi pada Tongkol Jagung (Zea Mays) sebagai Adsorben Ion Logam Pb2+, Jurnal Kimia Sains dan Aplikasi, 17, 1, (2014) $31-36$

[3] Sriyanti Sriyanti, Taslimah Taslimah, Evaluasi Model Langmuir-Hinshelwood untuk Kinetika Adsorpsi Besi(III) pada 2-MerkaptobenzotiazolZeolit Alam, Jurnal Kimia Sains dan Aplikasi, 7, 2, (2004) 39-45

[4] Diana Nur Al-Latief, Arnelli, Yayuk Astuti, Synthesis of sodium lauryl sulphate (SLS)-modified activated carbon from risk husk for waste lead $(\mathrm{Pb})$ removal, AIP Conference Proceedings, 1699, 1, (2015) 060017 http://dx.doi.org/10.1063/1.4938371

[5] M. Alvien Ghifari, Arofah Nuraini, Dessy Permatasari, Nur Kamila, Teguh Imanullah, Yayuk Astuti, Nano-Zeolite Modification Using Cetylpiridinium Bromide for the Removal of Remazol Black B and Remazol Yellow G Dyes, Advanced Science Letters, 23, 7, (2017) 6502-6505 http://dx.doi.org/10.1166/asl.2017.9667

[6] Motoyuki Suzuki, Adsorption engineering, Kodansha, 1990
[7] Titi Agustin, Nor Basid Adiwibawa Prasetya, Didik Setiyo Widodo, Sintesis Komposit TiO2-Karbon Aktif untuk Fotokatalisis Larutan Zat Warna Direct Blue 19 dan Ion Logam $\mathrm{Pb}_{2}+$ dan $\mathrm{Cd} 2+$ secara Simultan, Jurnal Kimia Sains dan Aplikasi, 16, 3, (2013) 102-107 http://dx/doi.org/10.14710/jksa.16.3.102107

[8] Marina Adriati, Ahmad Suseno, Taslimah Taslimah, Modifikasi Zeolit Alam Menggunakan Besi (Fe) dan Kobalt (Co) untuk Katalis Degradasi Fenol, Jurnal Kimia Sains dan Aplikasi, 16, 1, (2013) 1-5 http://dx.doi.org/10.14710/jksa.16.1.1-5 